\title{
ASPECTOS BOTÂNICOS E ECOSSISTÊMICOS COMO SUBSÍDIO À INTERPRETAÇÃO AMBIENTAL NA TRILHA DO PARQUE MUNICIPAL FARROUPILHA, OESTE DO PARANÁ
}

Thais de Fátima Balbino Lisboa ${ }^{1}$ Roque Cielo-Filho ${ }^{2}$ Carla Daniela Câmara ${ }^{3}$ Willian Bogler da Silva ${ }^{4}$

Resumo: Este estudo teve como objetivo fornecer informações botânicas e ecológicas que subsidiaram a elaboração de um roteiro interpretativo para a trilha do Parque Municipal Farroupilha, localizado na região Oeste do Estado do Paraná, Brasil. Para atender a esse objetivo foi realizado o levantamento de informações fitogeográficas e florísticas da vegetação do Parque, a identificação de 30 elementos arbóreos de destaque presentes na trilha; e a compilação de informações sobre as espécies correspondentes, tais como ameaça de extinção, importância econômica, medicinal e alimentar. Foram elaborados textos para confecção de painéis abordando sete temas relacionados aos atributos naturais e interações ecológicas visíveis no Parque.

Palavras-chave: Trilha Interpretativa; Ecologia; Botânica; Educação Ambiental.

${ }^{2}$ Instituto Florestal - Secretaria do Meio Ambiente/SP. E-mail: roque@if.sp.gov.br

${ }^{3}$ Universidade Tecnológica Federal do Paraná. E-mail: camara@utfpr.edu.br

${ }^{4}$ Universidade Tecnológica Federal do Paraná. E-mail: willianbogler@hotmail.com

Revbea, São Paulo, V.11, № 2: 74-90, 2016. 


\section{Introdução}

Nos últimos anos, o Brasil tem avançado nas medidas de proteção do ambiente natural por meio de diferentes linhas de atuação, entre as quais as ações educativas ambientais e a definição de áreas naturais protegidas ou unidades de conservação (CAZOTO; TOZONI-REIS, 2008).

A criação de unidades de conservação (UCs) constitui uma estratégia para proteção da biodiversidade. As UCs são divididas em dois grupos: Unidades de Proteção Integral, onde só é permitido o uso indireto dos recursos naturais e atividades como pesquisas científicas, turismo ecológico, visitação, educação e interpretação ambiental; e Unidades de Uso Sustentável, onde o uso direto dos recursos naturais é permitido desde que haja garantia da perenidade dos recursos ambientais renováveis e dos processos ecológicos (OLIVEIRA; BARBOSA, 2010).

Segundo Brasil (2000), dentre as categorias de Unidades de Conservação Integral encontram-se os Parques Nacionais, Reservas Biológicas, Estações Ecológicas, Monumentos Naturais e Refúgios da Vida Silvestre; os quais podem ser nacionais, estaduais ou municipais, de acordo com o âmbito administrativo do contexto no qual são criados. O Parque Ecológico Farroupilha, local onde foi realizado o presente estudo, é uma Unidade de Conservação que se enquadra em um ramo derivado da categoria de Parque Nacional, denominado Parque Natural Municipal, pois foi criado em âmbito municipal, pelo Município de Matelândia, localizado no Estado do Paraná.

As UCs representam um cenário favorável para a Educação Ambiental, pois abrigam em seu interior diversos elementos naturais que podem ser utilizados no desenvolvimento de ações voltadas a sensibilização dos visitantes da área protegida. A interpretação ambiental é uma atividade preconizada nos objetivos dos Parques Nacionais, podendo ser utilizada como uma ferramenta da Educação Ambiental e contribuindo para otimizar a experiência que os visitantes podem vivenciar nas UCs, auxiliando-os no aprendizado de diversas temáticas, desde assuntos relacionados a unidade até as questões mais abrangentes como o papel da conservação no mundo, o que pode influenciar nas mudanças de atitudes e valores (NELSON, 2012, p. 218).

A interpretação ambiental é vista por Silva e Júnior (2010) como um dos aspectos mais importantes a ser considerado nos planos de manejo das UCs, pois integra positivamente os visitantes as unidades. Uma das práticas de interpretação ambiental muito usada é a trilha interpretativa, a qual segundo Silva e Júnior (2010), não se resume a um espaço geográfico traçado para a mobilidade física ou para a contemplação de espaços naturais, mas devem ser caminhos que contenham significados históricos, culturais ou ecológicos, e que estes sejam revelados ao público visitante através de estratégias interpretativas. Para Menghini (2005, p. 44), a trilha interpretativa consiste num instrumento pedagógico importante que possibilita o conhecimento do meio ambiente e das interações que ocorrem nele, bem como o desenvolvimento de atitudes e valores nos indivíduos. 
A interpretação ambiental em trilhas interpretativas pode ser realizada com a presença de um guia, tecnicamente capacitado, sendo denominada de trilha guiada; ou sem o acompanhamento de um guia, fazendo-se uso de outros recursos interpretativos, tais como recursos visuais, gráficos, placas com informações de árvores nativas ou temas (mata ciliar, recursos hídricos, etc.), tratando-se de uma trilha autoguiada (SÃO PAULO, 2008).

Silva e Júnior (2010) destacam a importância da vegetação para as atividades de interpretação ambiental em trilhas, mencionando aspectos como a estrutura da floresta composta pelas árvores; a vegetação enquanto biomassa visível de maior abundância; a imobilidade das árvores, as quais não podem se deslocar como os animais, o que possibilita um maior contato com as pessoas; dentre outros. Tais características conferem às espécies arbóreas um rico potencial interpretativo e educativo. Além disso, as espécies arbóreas merecem destaque em trilhas interpretativas devido a sua grande importância ecológica e econômica, considerando o suprimento de diferentes tipos de necessidades humanas.

A ausência de informações sobre aspectos botânicos e características ecológicas, históricas e econômicas da vegetação do Parque Farroupilha dificultava a elaboração de um roteiro interpretativo para a trilha ecológica já existente no Parque. O presente trabalho objetivou o levantamento de tais informações, o que facilitou a identificação dos potenciais interpretativos da trilha servindo de subsídio para a elaboração de um projeto de interpretação ambiental através da comunicação visual para a trilha do Parque.

\section{Metodologia}

Para atender ao objetivo proposto foi realizado o levantamento de informações fitogeográficas e florísticas da vegetação do Parque; a identificação de 30 elementos arbóreos de destaque presentes na trilha e a compilação de informações sobre as espécies correspondentes, incluindo nome científico e vernáculo, uso popular, características ecológicas e importância econômica; e elaboração de textos que abordam temas relacionados aos atributos históricos, naturais e ecológicos presentes no Parque.

A seleção das árvores que foram identificadas foi realizada percorrendose a trilha do Parque em toda sua extensão e ao longo do percurso foram escolhidos 30 elementos arbóreos que se destacavam em função de aspectos como porte, características ecológicas, importância econômica e risco de extinção. Em seguida, foi coletado material botânico das árvores escolhidas, o qual foi processado de acordo com técnicas usuais de herborização (ROTTA et al., 2008).

A identificação do material botânico coletado foi realizada no herbário Dom Bento José Pickel (SPSF) no Instituto Florestal de São Paulo, onde tanto os materiais férteis como os estéreis foram identificados, obtendo-se o nome científico e a família. Os nomes populares foram obtidos por meio de consultas 
a moradores locais. As espécies foram ordenadas em famílias e gêneros de acordo com o sistema proposto pelo Grupo de Filogenia de Angiospermas (APG III, 2009). Para a verificação das grafias e sinonímias botânicas foi consultada a Lista de Espécies da Flora do Brasil (FORZZA et al., 2015).

Seguindo o procedimento adotado em Cielo-Filho et al. (2010), após a identificação das espécies arbóreas, foram obtidas informações na literatura quanto ao grupo ecológico (pioneiras e não-pioneiras) e à síndrome de dispersão (zoocóricas, anemocóricas e autocóricas) das espécies. Em relação à importância ecológica e econômica, foram compiladas informações quanto às indicações das espécies para restauração de áreas degradadas, uso na indústria madeireira, uso medicinal, uso na alimentação e aquelas que possuem características ornamentais. As características ecológicas e a importância econômica das espécies foram compiladas a partir de Lorenzi (1992), Lorenzi (1998), Carvalho (2003), Carvalho (2006), Carvalho (2008), Carvalho (2010), Backes e Irgang (2004).

Também verificou-se as espécies ameaçadas de extinção, tomando como base a Lista Vermelha de Plantas Ameaçadas de Extinção no Estado do Paraná da Secretaria de Estado do Meio Ambiente - SEMA-PR (PARANÁ, 1995) e a Lista Nacional Oficial de Espécies da Flora Ameaçadas de Extinção do Ministério do Meio Ambiente - MMA (BRASIL, 2014). A lista SEMA-PR classifica as espécies ameaçadas nas categorias: Rara, Vulnerável (VU) e Em Perigo (EN). A lista MMA classifica as espécies nas seguintes categorias: Extinta (EX), Extinta na Natureza (EW), Criticamente em Perigo (CR), Em Perigo (EN) e Vulnerável (VU).

Além do levantamento de informações sobre os 30 elementos arbóreos identificados, também foi realizada uma pesquisa bibliográfica sobre os atributos históricos, naturais e interações ecológicas presentes no Parque Farroupilha. Foram selecionados temas que contemplassem elementos naturais e interações ecológicas que ocorrem em seu interior, levando-se em consideração critérios como relevância do papel desempenhado na manutenção do ecossistema e facilidade de abordagem para comunicação visual. Foram coletadas informações sobre os seguintes temas: o tipo de vegetação, histórico do Parque, importância da conservação dos remanescentes de vegetação natural da região, papel das lianas no ecossistema, ciclo da água, ciclagem de nutrientes e dinâmica de clareiras. Cada um dos temas abordados foi usado para elaboração de placas interpretativas para a trilha do Parque.

\section{Resultados}

Através da pesquisa bibliográfica sobre os temas elencados obteve-se as informações abaixo, as quais foram utilizadas para elaboração de textos para os painéis interpretativos, tais textos encontram-se na Tabela 1.

revista brasileira educação ambiental 


\section{Tema "Histórico do Parque Farroupilha"}

Esse tema foi definido com o intento de informar aos visitantes sobre a importância, criação e objetivos do Parque, assim como expor as atividades que a Unidade de Conservação apoia e fomenta.

O Parque Ecológico Farroupilha é uma unidade de conservação, com área de $22.000 \mathrm{~m}^{2}$, pertencente à Prefeitura Municipal de Matelândia. O Parque foi criado em setembro de 2004, no local onde anteriormente existia um mini zoológico, tendo como objetivos a preservação do ecossistema natural, o desenvolvimento de atividades de educação e interpretação ambiental, dentre outros.

\section{Tema "Dinâmica de Clareiras"}

O tema é referente à marcante característica de formação de clareiras presente no Parque Farroupilha, devido à queda de árvores inteiras ou de galhos durante temporais. Entre os espécimes caídos, está um exemplar de grande porte da espécie Aspidosperma polyneuron.

A clareira pode ser definida, segundo Leitão Filho e Morellato (1995, p. 30), como "uma abertura do dossel da floresta devido à queda de uma ou mais árvores ou parte delas". A clareira possui um importante papel na regeneração natural, pois ela cria as devidas condições para que aconteça o processo de regeneração, que pode ocorrer de três formas: regeneração via sementes, regeneração via plântulas e regeneração por meio da rebrota de indivíduos sobreviventes ou daqueles no dossel adjacente (HUBBELL; FOSTER, 1986 apud LIMA, 2005 p. 659). O processo de regeneração natural garante a renovação dos indivíduos e a perenidade das espécies do ecossistema (PUIG, 2008, p. 276).

\section{Tema "O Ciclo Hidrológico"}

O tema busca valorizar a importância dos recursos hídricos. É representado no interior do Parque por uma fonte de água e dois lagos artificiais contendo peixes.

Odum e Barrett (2007, p. 156) afirmam que a energia solar se faz presente em boa parte do ciclo da água, o qual além de envolver a evaporação da água dos oceanos, também utiliza a evapotranspiração como modo de repor a água para atmosfera. Autores como Odum e Barrett (2007, p 157), Lorenzi (1992); Tundisi e Tundisi (2010, p. 68) apontam a importância da vegetação no ciclo hidrológico, no qual esta possui papel ativo, pois absorve o excesso de água das chuvas, que eventualmente escorrem pela superfície dos solos, e promove a volta de parte da água precipitada para a atmosfera sob forma gasosa, através da evaporação e transpiração dos vegetais. 


\section{Tema "A Importância da Conservação dos Remanescentes de Vegetação Natural da Região e Fragmentos Florestais Urbanos"}

Tema com destaque para a importância dos papéis desempenhados pela vegetação nativa e pelas florestas urbanas, como o fragmento florestal presente no Parque Farroupilha, e para a importância de conservá-las.

Segundo Lorenzi (1992), o Brasil possui a flora arbórea mais diversificada do mundo, mas a exploração exagerada dos recursos florestais acarretou em prejuízos irreparáveis, como a fragmentação de ambientes naturais que se configura em uma das maiores ameaças à diversidade biológica. Leitão Filho e Morellato (1995, p. 15) salientam a importância de se proteger fragmentos florestais, mesmo se tratando de áreas que não são constituídas por vegetação primária ou que tenham sido submetidas a diferentes tipos de perturbações. Para os autores, "o objetivo da conservação não é preservar algum ideal de floresta ou vegetação primária e intocada e sim proteger a diversidade". A vegetação presente em ambiente urbano promove benefícios ambientais sob diferentes aspectos, tais como o controle microclimático e a minimização da poluição e do ruído (COSTA; COLESANTI, 2011, p. 241).

\section{Tema "Tipo de Vegetação"}

O tema é referente ao tipo de vegetação encontrado no Parque Farroupilha, suas características e importância para conservação.

A formação vegetal predominante dos fragmentos de floresta nativa da região onde encontra-se o Parque Farroupilha é a Floresta Estacional Semidecidual (DI BITETTI et al., 2003). Esse tipo de vegetação possui como características a dupla estacionalidade climática (CARVALHO, 2003, p. 35) e a semideciduidade da folhagem da cobertura vegetal (IBGE, 2012). Do ponto de vista fitogeográfico, a Floresta Estacional Semidecidual do Parque Farroupilha pode ser considerada pertencente a Ecorregião Florestas do Alto Paraná, a qual possui um dos maiores blocos de floresta remanescente. Essa ecorregião figura no Complexo de Ecorregiões da Mata Atlântica, que se encontra entre as florestas tropicais mais ameaçadas do mundo (DI BITETTI et al., 2003).

\section{Tema "Ciclagem de Nutrientes"}

Tema inspirado nas diversas interações e processos ecológicos presentes no Parque. Um dos processos mais conspícuos para o público visitante é a decomposição microbiana perceptível em troncos de árvores mortas caídos em clareiras dispersas pelo Parque.

A reciclagem de nutrientes é um processo essencial em ecossistemas, podendo ser realizado por meio da decomposição microbiana, por excreções animais, por reciclagem entre plantas através de simbiose com microrganismos, dentre outros (ODUM; BARRET, 2007, p. 172). A deposição e decomposição de serapilheira também fazem parte do processo de ciclagem de nutrientes. A 
serapilheira é definida por Brun et al. (2011, p. 196) como "todos os tipos de material biológico em vários estágios de decomposição, o qual representa uma fonte potencial de energia para as espécies consumidoras". Para Ricklefs (2010) a serapilheira é a base das cadeias alimentares de detritos nos solos florestais, onde juntamente com excretas de animais e outros restos orgânicos é decomposta, liberando seus nutrientes no ambiente e possibilitando a sua reutilização pelas plantas.

\section{Tema "O Papel das Lianas no Ecossistema"}

Esse tema é referente ao importante papel desempenhado pelas lianas no ecossistema, com propósito de chamar atenção para os exuberantes exemplares de lianas presentes no Parque.

As lianas são plantas trepadeiras importantes para a composição e estrutura de florestas tropicais (ENGEL et al., 1998, p. 49). Essas plantas constituem um componente florestal não arbóreo que contribui de forma significativa para a diversidade vegetal. Elas também auxiliam a ciclagem e conservação de nutrientes, ajudando na retenção destes na biomassa (ENGEL et al.,1998, p. 60). As lianas produzem folhas ao longo de todo o ano, o que beneficia a fauna, através da oferta de proteção e abrigo e da disponibilidade de recursos para animais frugívoros e folhívoros. A importância das lianas no ecossistema pode ser verificada através de suas contribuições e características particulares aqui citadas. 
Tabela 1: Textos elaborados para os painéis interpretativos e bibliografia consultada para a compilação das informações.

(continua)

Tema

Histórico do Parque Farroupilha

Texto elaborado para o painel

Bem-vindo ao Parque Ecológico Farroupilha. O Parque Ecológico Farroupilha é uma unidade de conservação da natureza! Possui uma área de $22.000 \mathrm{~m}^{2}$ e abriga em seu interior diferentes espécies de plantas e animais. Mas esse local nem sempre foi assim... em 1979 no local onde atualmente localiza-se o Parque existia um mini zoológico. Depois que o zoológico foi fechado, a área ficou desprotegida, havendo a necessidade da criação de uma unidade de conservação. E assim, em 2004, foi criado o Parque Ecológico Farroupilha com o objetivo de preservar e proteger a biodiversidade local. Além disso, o Parque também estimula a realização de pesquisas científicas, o desenvolvimento de atividades de educação e interpretação ambiental, e a recreação em contato com a natureza.
Dinâmica

Clareiras de

clareiras? Quando uma ou várias árvores, ou até partes delas caem, se cria uma abertura no meio da floresta. Esse espaço aberto entre as árvores é chamado de clareira. Como ocorrem as clareiras? As clareiras podem ser formadas por diversos fatores, como a derrubada de árvores, ventos fortes, secas ou morte das árvores por ataque de pragas e doenças. A abertura das clareiras é um processo natural que pode ser encontrado em florestas espalhadas por todo o planeta. A clareira possui um importante papel na estrutura da floresta, pois ela promove a diversidade de espécies e garante que a floresta esteja sempre se renovando.
Bibliografia consultada

Matelândia (2004),
Matelândia (2010).
Prefeitura Municipal de

Leitão Filho; Morellato (1995), Puig (2008), Hubbell; Foster (1986), Lima (2005).

\section{Odum; Barrett (2007)} Lorenzi (1992), Tundisi; que torna possível existir vida aqui. Pena que nem toda essa água pode ser consumida... e o pouquinho que podemos usar está desaparecendo dos rios... Mas para onde será que a água vai??? No ciclo da água, ela evapora dos oceanos para a atmosfera e depois volta para a Terra, em formato de chuva, granizo ou neve; infiltra no solo e retorna para os rios, lagos, oceanos ou outros corpos d'água Sabia que as árvores também têm um papel muito importante nesse ciclo? Elas absorvem o excesso de água das chuvas e mandam essa água de volta para atmosfera através da evaporação e transpiração. A água não está acabando, ela está sempre em movimento. E para preservarmos o pouco que temos para consumo, devemos combater o desmatamento, o desperdício e a poluição.

\footnotetext{
A importância da Conservação dos Remanescentes de Vegetação Natura da Região e de Fragmentos

Florestais Urbanos

Você sabia que o Brasil possui a flora arbórea mais diversificada do mundo?? Mas infelizmente a exploração exagerada dos recursos florestais trouxe grandes prejuízos a natureza, como a fragmentação das florestas. A fragmentação florestal é a divisão de uma floresta em pedaços menores, e isso diminui a diversidade de espécies. É importante a proteção dos fragmentos florestais urbanos, como a floresta presente no Parque Farroupilha, pois além de conservar a biodiversidade local, essas florestas também promovem benefícios ambientais como controle micro-climático e minimização da poluição e do barulho. A floresta, seja ela grande ou pequena, tem participação no ciclo da áqua, na alimentação dos animais e na proteção do solo e dos corpos d'água.
} 
Tabela 1: Textos elaborados para os painéis interpretativos e bibliografia consultada para a compilação das informações.

(conclusão)

Tema

Texto elaborado para o painel

Bibliografia

consultada

\begin{tabular}{|c|c|c|}
\hline Tipo de Vegetação & $\begin{array}{l}\text { A floresta presente na região onde se encontra o Parque Farroupilha é a Floresta Estacional Semidecidual. E por que } \\
\text { esse nome tão esquisito? Estacional, está relacionado ao clima presente na região, o clima subtropical, que apresenta } \\
\text { duas estações climáticas, sem período de seca, mas com inverno bastante frio. Semidecidual se refere a vegetação } \\
\text { que perde parte de suas folhas no inverno. A Floresta Estacional Semidecidual do Parque Farroupilha faz parte do } \\
\text { bioma Mata Atlântica, que se encontra entre as florestas tropicais mais ameaçadas do mundo, possuindo hoje apenas } \\
7,4 \% \text { de sua cobertura florestal original. No Brasil, o bioma Mata Atlântica estende-se desde o Nordeste até a região } \\
\text { Sul do país. A Mata Atlântica já foi muito explorada, temos que proteger o que nos restou! }\end{array}$ & $\begin{array}{l}\text { Leitão } \\
\text { Morellato (1995), } \\
\text { Di Bitetti et al. } \\
\text { (2003), Carvalho } \\
\text { (2003), IBGE } \\
\text { (2012), Embrapa } \\
(2011) .\end{array}$ \\
\hline $\begin{array}{l}\text { Ciclagem } \\
\text { Nutrientes }\end{array}$ & $\begin{array}{l}\text { Os nutrientes estão sempre circulando entre os seres vivos e o ambiente. E como isso acontece? As plantas } \\
\text { absorvem os nutrientes presentes no solo e esses nutrientes são passados aos animais que se alimentam das plantas } \\
\text { e de outros animais. Mas como os nutrientes voltam para o ambiente? A volta dos nutrientes para o solo pode ocorrer } \\
\text { de várias formas, uma delas é através da decomposição microbiana. É quando plantas e animais morrem e alguns } \\
\text { microrganismos decompõem seus restos mortais, assim os nutrientes presentes neles vão para o solo, de volta ao } \\
\text { ambiente; ou também quando a serapilheira, constituída por folhas e galhos das plantas que caem no chão da floresta, } \\
\text { é decomposta por esses microrganismos liberando também nutrientes para o ambiente. A ciclagem de nutrientes é } \\
\text { muito importante para o desenvolvimento das plantas e para nossa sobrevivência, pois dependemos delas para nos } \\
\text { alimentar! }\end{array}$ & $\begin{array}{lr}\text { Odum; } & \text { Barrett } \\
\text { (2007), Brun et al. } \\
(2011), \quad \text { Ricklefs } \\
(2010) .\end{array}$ \\
\hline $\begin{array}{l}\text { O Papel das Lianas } \\
\text { no Ecossistema }\end{array}$ & $\begin{array}{l}\text { As lianas são plantas de caule longo e flexível, herbáceo ou lenhoso, que crescem apoiadas em árvores ou arbustos. } \\
\text { Essas plantas buscam o topo das árvores a procura de luz para se desenvolver, e o peso delas pode provocar danos } \\
\text { às copas das árvores. Mas as lianas não são plantas prejudiciais, elas beneficiam o ecossistema de várias maneiras: } \\
\qquad \text { Os caules das lianas formam uma rede de comunicação para os animais se locomoverem. } \\
\checkmark \quad \text { Elas também produzem folhas, flores e frutos o ano todo e isso beneficia os animais, lhes ofertando proteção, } \\
\text { abrigo e alimento. }\end{array}$ & $\begin{array}{lrr}\text { Engel } & \text { et } & \text { al. } \\
(1998), & & \text { Puig } \\
(2008), & & \text { Putz } \\
(1984), & \text { Uhl; } & \text { Vieira } \\
(1989) . & & \end{array}$ \\
\hline
\end{tabular}


Quanto às espécies arbóreas selecionadas para fazerem parte da trilha interpretativa, as informações obtidas sobre cada uma delas encontram-se na Tabela 2.

Os 30 indivíduos arbóreos identificados pertencem a 28 espécies, sendo duas exóticas: Eryobotria japonica e Persea americana; uma exótica regional: Caesalpinia echinata; e as demais nativas da região. Quanto ao grupo ecológico, nove espécies são pioneiras e 19 são não-pioneiras. Em relação a síndrome de dispersão, 15 espécies são zoocóricas, nove anemocóricas e cinco autocóricas. Dez espécies apresentam importância madeireira, oito são especialmente úteis na restauração ecológica, seis podem ser úteis para a alimentação, cinco são ornamentais, duas são consideradas medicinais e uma apresenta importância econômica devido à produção de paina (Tabela 2). Três espécies estão ameaçadas de extinção em nível nacional: Euterpe edulis, Cedrela fissilis e Caesalpinia echinata; e cinco espécies são consideradas raras em nível estadual: Holocalyx balansae, Jacaratia spinosa, Aspidosperma polyneuron, Balfourodendron riedelianum e Myrocarpus frondosus.

Pode-se observar que, apesar de terem sido selecionados poucos indivíduos relativamente ao tamanho do fragmento, eles exemplificam todas as características propostas na Tabela 2, tais como vulnerabilidade à extinção, características econômicas e ecológicas. A partir dessas informações, o visitante poderá associar a importância direta dessas espécies no seu cotidiano à necessidade de ações de preservação.

Um exemplo a ser destacado é o palmito juçara (Euterpe edulis), explorado ilegalmente em unidades de conservação (OLIVEIRA et al., 2010) e comercializado na forma de produtos alimentares. A informação sobre a vulnerabilidade da espécie à extinção poderá sensibilizá-lo a não adquirir tais produtos. Já o jacaratiá (Jacaratia spinosa), amplamente utilizado na alimentação, figura como espécie rara, o que pode sugerir ao visitante a necessidade do uso racional da espécie, bem como de reposição da mesma em áreas onde é explorada.

Informações ecológicas, como a síndrome de dispersão, poderão despertar o interesse do visitante sobre a interdependência entre a fauna e a vegetação. Essa relação pode ser destacada no grupo de espécies estudado, no qual a zoocoria predomina entre as três formas de dispersão identificadas. Essa informação pode ser amplamente explorada em programas de educação ambiental, visando a sensibilização do visitante sobre as conseqüências da caça e do tráfico de animais silvestres.

Outra característica com grande potencial de sensibilização para o visitante é a importância medicinal, a qual foi indicada para a cabreúva-amarela (Myrocarpus frondosus) e o acoita-cavalo (Luehea divaricata). 
Tabela 2: Relação das espécies arbóreas marcadas ao longo das trilhas do Parque Ecológico Farroupilha com características ecológicas e importância econômica. Espécies ameaçadas de extinção segundo a Lista das Espécies da Flora Brasileira Ameaçadas de Extinção - MMA e a Lista Vermelha de Plantas Ameaçadas de Extinção no Estado do Paraná - SEMA-PR. VU = Vulnerável, EN = Em Perigo.

(continua)

\begin{tabular}{|c|c|c|c|c|c|c|c|c|}
\hline Ordem & Nome popular & Família & Espécie (autor) & $\begin{array}{c}\text { Grupo } \\
\text { sucessional }\end{array}$ & $\begin{array}{l}\text { Síndrome de } \\
\text { dispersão }\end{array}$ & $\begin{array}{r}\text { Am } \\
\text { Ex } \\
\text { MMA }\end{array}$ & $\begin{array}{l}\text { aça de } \\
\text { nção } \\
\text { SEMA - } \\
\text { PR }\end{array}$ & Importância \\
\hline 1 & pau-brasil & Fabaceae & Caesalpinia echinata Lam. & Não-pioneira & Autocoria & EN & - & Madeireira $^{1}$ \\
\hline 2 & canelinha & Lauraceae & Nectandra megapotamica (Spreng.) Mez & Não-pioneira & Zoocoria & - & - & Madeireira² \\
\hline 3 & canjerana & Meliaceae & Cabralea canjerana (Vell.) Mart. & Não-pioneira & Zoocoria & - & - & Madeireira ${ }^{3}$ \\
\hline 4 & cabreúva-amarela & Fabaceae & Myrocarpus frondosus Allemão & Não-pioneira & Anemocoria & - & RARA & Medicinal $^{4}$ \\
\hline 5 & peroba-rosa & Apocynaceae & Aspidosperma polyneuron Müll. Arg. & Não-pioneira & Anemocoria & - & RARA & Madeireira $^{5}$ \\
\hline 6 & caroba & Bignoniaceae & Jacaranda micrantha Cham. & Pioneira & Anemocoria & - & - & Ornamental $^{6}$ \\
\hline 7 & pau-marfim & Rutaceae & Balfourodendron riedelianum (Engl.) Engl. & Não-pioneira & Anemocoria & - & RARA & Madeireira ${ }^{7}$ \\
\hline 8 & angico-vermelho & Fabaceae & Parapiptadenia rigida (Benth.) Brenan & Não-pioneira & Autocoria & - & - & Madeireira $^{8}$ \\
\hline 9 & figueira & Moraceae & Ficus insipida Willd. & Pioneira & Zoocoria & - & - & Restauração ${ }^{\circ}$ \\
\hline 10 & paineira & Malvaceae & Ceiba speciosa (A.St.-Hil.) Ravenna & Não-pioneira & Anemocoria & - & - & Paina ${ }^{10}$ \\
\hline
\end{tabular}

'Madeira usada em construção civil. Atualmente, sua madeira é muito utilizada na fabricação de instrumentos musicais, principalmente na confecção de arco de violino, por apresentar muita flexibilidade.

2Madeira maciça ou em chapas para placas e compensados destinados a revestimentos internos e à fabricação de móveis.

${ }^{3}$ Fornece madeira com qualidades próximas às do cedro (Cedrela fissilis), sendo mais durável, madeira indicada para a confecção de estruturas de móveis, marcenaria, construção civil.

${ }^{4} \mathrm{Na}$ medicina popular, a seiva é usada no tratamento de doenças pulmonares, constituindo um expectorante peitoral e excitante difusivo, indicado para lesões do aparelho respiratório, propriedade extensiva à raiz.

${ }^{5}$ Entre as espécies de Aspidosperma, a peroba-rosa é a espécie de maior valor econômico. Sua madeira é usada na indústria de móveis e indicada, principalmente, em construção civil, construção naval e canoas.

${ }^{6}$ Espécie muito ornamental pela beleza de suas flores, sendo usada em parques, avenidas e em arborização de rodovias.

${ }^{7}$ Madeira indicada para fabricação de móveis de luxo, partes internas na construção civil, artefatos decorativos em geral.

${ }^{8}$ Madeira de durabilidade natural alta, resistência mecânica e retratibilidade médias, indicada para construção rural e civil.

${ }^{9}$ É indicada para a composição de reflorestamentos heterogêneos destinados à recomposição de áreas ciliares degradadas.

${ }^{10} \mathrm{~A}$ paineira apresenta grande valor econômico pelas excelentes características e alto preço da paina, que pode ser usada como isolante térmico ou acústico. Pode também ser usada como enchimento de travesseiros, almofadas, colchões, estofaria de móveis, na fabricação de equipamentos de flutuação e de salva-vidas. 
Tabela 2: Relação das espécies arbóreas marcadas ao longo das trilhas do Parque Ecológico Farroupilha com características ecológicas e importância econômica. Espécies ameaçadas de extinção segundo a Lista das Espécies da Flora Brasileira Ameaçadas de Extinção - MMA e a Lista Vermelha de Plantas Ameaçadas de Extinção no Estado do Paraná - SEMA-PR. VU = Vulnerável, EN = Em Perigo.

(continua)

\begin{tabular}{|c|c|c|c|c|c|c|c|c|}
\hline Ordem & Nome popular & Família & Espécie (autor) & $\begin{array}{c}\text { Grupo } \\
\text { sucessional }\end{array}$ & $\begin{array}{l}\text { Síndrome de } \\
\text { dispersão }\end{array}$ & $\begin{array}{r}\text { Am } \\
\text { Ex } \\
\text { MMA }\end{array}$ & $\begin{array}{l}\text { aça de } \\
\text { nção } \\
\text { SEMA - } \\
\text { PR }\end{array}$ & Importância \\
\hline 11 & goiabão-do-mato & Meliaceae & Trichilia clausseni C. DC. & Não-pioneira & Zoocoria & - & - & Ornamental ${ }^{11}$ \\
\hline 12 & guapuriti & Myrtaceae & Plinia rivularis (Cambess.) Rotman & Não-pioneira & Zoocoria & - & - & Madeireira ${ }^{12}$ \\
\hline 13 & tapiá & Euphorbiaceae & Alchornea glandulosa Poepp. \&Endl. & Pioneira & Zoocoria & - & - & Restauração ${ }^{13}$ \\
\hline 14 & aguaí-da-serra & Sapotaceae & $\begin{array}{c}\text { Chrysophyllum gonocarpum (Mart. \& Eichler ex } \\
\text { Miq.) Engl. }\end{array}$ & Não-pioneira & Zoocoria & - & - & Alimentação ${ }^{14}$ \\
\hline 15 & branquinho & Euphorbiaceae & Sebastiania brasiliensis Spreng. & Pioneira & Autocoria & - & - & Ornamental $^{15}$ \\
\hline 16 & jacaratiá & Caricaceae & Jacaratia spinosa (Aubl.) A. DC. & Não-pioneira & Zoocoria & - & RARA & $\begin{array}{l}\text { Alimentação } 0^{16} \mathrm{~A} \\
\text { Restauração } 0^{16 \mathrm{~B}}\end{array}$ \\
\hline 17 & candiúva & Cannabaceae & Trema micrantha (L.) Blume & Pioneira & Zoocoria & - & - & Restauração ${ }^{17}$ \\
\hline 18 & peroba-rosa & Apocynaceae & Aspidosperma polyneuron Müll. Arg. & Não-pioneira & Anemocoria & - & RARA & Ornamental $^{18}$ \\
\hline 19 & alecrim & Fabaceae & Holocalyx balansae Micheli & Não-pioneira & Zoocoria & - & - & Madeireira ${ }^{19}$ \\
\hline 20 & taiúva & Moraceae & Maclura tinctoria (L.) D. Don ex Steud. & Não-pioneira & Zoocoria & - & - & Alimentação ${ }^{20}$ \\
\hline
\end{tabular}

${ }^{11 A ́ r v o r e ~ r e c o m e n d a d a ~ p a r a ~ o ~ p a i s a g i s m o ~ e m ~ g e r a l ; ~ e ́ ~ p a r t i c u l a r m e n t e ~ u ́ t i l ~ p a r a ~ a r b o r i z a c ̧ a ̃ o ~ d e ~ r u a s ~ e s t r e i t a s . ~}$

${ }^{12} \mathrm{~A}$ madeira pode ser empregada para pequenas obras de construção civil, confecção de móveis simples, cabos de ferramentas, embalagens e engradados.

${ }^{13}$ Como planta pioneira e rústica, não pode faltar nos plantios mistos destinados à recomposição de áreas degradadas de preservação permanente. É indicada, também, para restauração de ambientes ripários, onde suporta inundação.

${ }^{14}$ Os frutos dessa espécie são doces e comestíveis, usados na fabricação de sorvetes caseiros e na preparação de doces, vendidos em mercados populares na Argentina e no Paraguai.

${ }^{15}$ Árvore de pequeno porte e copa muito ornamental, pode ser aproveitada com sucesso para o paisagismo, principalmente para a arborização de ruas estreitas e sob redes elétricas.

${ }^{16} \mathrm{AO}$ fruto é doce, com sabor semelhante ao mamão, mas leitoso e cáustico. Por isso, só deve ser usado quando bem maduro ou assado no borralho. Com a parte macia do caule ou da raiz, faz-se uma massa que, misturada ao coco-da-bahia, serve para preparar um saboroso doce.

${ }^{16 \mathrm{BO}}$ jacaratiá produz muitos frutos comestíveis, importantes nas cadeias tróficas.

${ }^{17}$ Essa espécie apresenta grande versatilidade ecológica, sendo uma das espécies arbóreas pioneiras mais utilizadas em reflorestamento heterogêneo, na recuperação e na recomposição de áreas degradadas.

${ }^{18}$ É usada em paisagismo, principalmente em parques.

${ }^{19} \mathrm{~A}$ madeira pode ser usada em marcenaria de luxo, construção pesada. Algumas tribos indígenas fazem tacapes e pontas de flechas do cerne do alecrim.

$2^{20}$ Os frutos, suculentos e saborosos, são consumidos ao natural ou em sucos, ou ainda misturados ao vinho ou ao açúcar. 
Tabela 2: Relação das espécies arbóreas marcadas ao longo das trilhas do Parque Ecológico Farroupilha com características ecológicas e importância econômica. Espécies ameaçadas de extinção segundo a Lista das Espécies da Flora Brasileira Ameaçadas de Extinção - MMA e a Lista Vermelha de Plantas Ameaçadas de Extinção no Estado do Paraná - SEMA-PR. VU = Vulnerável, EN = Em Perigo.

(conclusão)

\begin{tabular}{|c|c|c|c|c|c|c|c|c|}
\hline \multirow[t]{2}{*}{ Ordem } & \multirow[t]{2}{*}{ Nome popular } & \multirow[t]{2}{*}{ Família } & \multirow[t]{2}{*}{ Espécie (autor) } & \multirow[t]{2}{*}{$\begin{array}{c}\text { Grupo } \\
\text { sucessional }\end{array}$} & \multirow[t]{2}{*}{$\begin{array}{l}\text { Síndrome de } \\
\text { dispersão }\end{array}$} & \multicolumn{2}{|c|}{$\begin{array}{l}\text { Ameaça de } \\
\text { Extinção }\end{array}$} & \multirow[t]{2}{*}{ Importância } \\
\hline & & & & & & $\begin{array}{c}\mathrm{MM} \\
\mathrm{A}\end{array}$ & $\begin{array}{l}\text { SEMA - } \\
\text { PR }\end{array}$ & \\
\hline 21 & guavirova & Myrtaceae & Campomanesia xanthocarpa (Mart.) O. Berg & Não-pioneira & Zoocoria & - & - & Alimentação21 \\
\hline 22 & piúna-preta & Myrtaceae & Plinia rivularis (Cambess.) Rotman & Não-pioneira & Zoocoria & - & - & Restauração22 \\
\hline 23 & cedro-rosa & Meliaceae & Cedrela fissilisVell. & Não-pioneira & Anemocoria & VU & - & $\begin{array}{c}\text { Madeireira }{ }^{23 \mathrm{~A}} \\
\text { Restauração }\end{array}$ \\
\hline 24 & peloteira & Meliaceae & Guarea kunthianaA.Juss. & Não-pioneira & Zoocoria & - & - & Restauração $0^{24}$ \\
\hline 25 & algodoeiro & Malvaceae & Bastardiopsis densiflora (Hook. \& Arn.) Hassl. & Pioneira & Anemocoria & - & - & Restauração ${ }^{25}$ \\
\hline 26 & abacateiro & Lauraceae & Persea americana Mill. & Pioneira & Autocoria & - & - & Alimentação ${ }^{26}$ \\
\hline 27 & açoita-cavalo & Malvaceae & Luehea divaricata Mart. \&Zucc. & Não-pioneira & Anemocoria & - & - & Medicinal $^{27}$ \\
\hline 28 & ameixeira & Rosaceae & Eriobotrya japonica (Thunb.) Lindl. & Pioneira & Zoocoria & - & - & Ornamental $^{28}$ \\
\hline 29 & maria-preta & Sapindaceae & Diatenopteryx sorbifolia Radlk. & Pioneira & Anemocoria & - & - & Madeireira 29 \\
\hline 30 & palmito-juçara & Arecaceae & Euterpe edulis Mart. & Não-pioneira & Zoocoria & VU & - & Alimentação ${ }^{30}$ \\
\hline
\end{tabular}

${ }^{21}$ Sua importância consiste, principalmente, no possível aproveitamento dos frutos em industrialização. São bagas ricas em vitamina C, que são consumidas in natura e usadas no preparo de licores.

22Indicada para reflorestamentos mistos destinados à recuperação da vegetação de áreas degradadas.

${ }^{23}$ Entre as madeiras leves, o cedro é a que possibilita o uso mais diversificado possível, superado somente pela madeira do pinheiro-do-Paraná (Araucaria angustifolia).

${ }^{23} \mathrm{~B} A$ pesar de apresentar fitotoxidez moderada, o cedro é considerado promissor para programas de revegetação de áreas com solo contaminado com metais pesados, tais como zinco $(\mathrm{Zn})$, cádmio $(\mathrm{Cd})$, chumbo $(\mathrm{Pb})$ e Cobre $(\mathrm{Cu})$.

${ }^{24}$ Os frutos são avidamente procurados por pássaros, principalmente o tucano, sendo por isso recomendável para a composição de reflorestamentos heterogêneos destinados à recuperação de áreas degradadas.

${ }^{25}$ Essa espécie suporta períodos de encharcamento e inundação moderados, sendo recomendada para a restauração de mata ciliar.

${ }^{26}$ Frutífera importante, de bom valor nutritivo, tem sua aplicação na alimentação, onde a polpa pode ser consumida doce ou salgada. As folhas podem ser utilizadas como tempero, substituindo o louro.

${ }^{27} \mathrm{O}$ chá da casca é usado para fazer bochechos no tratamento de inflamações da garganta, como analgésico para dor de dentes, depurador do sangue.

${ }^{28}$ Planta de sombra, ornamental para jardins e parques.

${ }^{29}$ A madeira pode ser usada em construção civil, carpintaria geral, carroçarias, pisos, móveis finos, cabos de ferramentas e objetos torneados.

$3^{30} \mathrm{O}$ valor comercial do palmiteiro consiste, principalmente, na utilização do palmito no preparo de conservas. Produto alimentício com larga aceitação no mercado nacional e internacional. 


\section{Expectativas de impacto da trilha sobre os visitantes}

Considera-se que o Parque Farroupilha, apesar de não possuir grande extensão territorial, possui em seu interior uma rica diversidade com grande potencial interpretativo. Espera-se que a trilha interpretativa potencialize a interação entre o público visitante e a Unidade de Conservação.

Considerando que todo esse potencial seja utilizado de maneira apropriada para a interpretação ambiental, servindo de atrativo para os visitantes, a trilha poderá subsidiar programas, estratégias e ações para sensibilizar a população acerca da importância da conservação dos recursos naturais.

Espera-se que os painéis temáticos contribuam para ampliar o conhecimento dos visitantes sobre as interações ecológicas que ocorrem nos ambientes florestais, bem como sobre a importância desses ambientes para as populações humanas. De posse desse conhecimento, o visitante poderá identificar, no seu cotidiano, ações que contribuam para a manutenção desses processos, como por exemplo: economia de água, interesse pela origem de produtos madeireiros e disseminação do conhecimento adquirido no meio social em que vive. Adicionalmente, espera-se do visitante um posicionamento favorável à preservação e à ampliação de remanescentes de vegetação nativa.

Com a correta identificação dos elementos arbóreos na trilha, os visitantes poderão buscar mais conhecimentos sobre as referidas espécies, bem como estabelecer relações de respeito para com aqueles indivíduos, que passarão a integrar o universo do visitante como um ser vivo com identidade própria.

\section{Referências}

APG III 2009. An update of the Angiospem Phylogeny Group classification for the orders and families of flowering plants: APG III. Botanical Journal of Linnean Society, v. 161, p. 105-121.

BACKES, P.; IRGANG, B.E. Árvores Cultivadas no Sul do Brasil: Guia de Identificação e Interesse Paisagístico das Principais Espécies Exóticas. Rio Grande do Sul: Paisagem do Sul, 2004. 204 p.

BRASIL. Lei no 9.985, de 18 de julho de 2000. Regulamenta o art. 225, § 10, incisos I, II, III e VII da Constituição Federal, institui o Sistema Nacional de Unidades de Conservação da Natureza e dá outras providências. Diário Oficial da União, 19 jul. 2000.

BRASIL. Ministério do Meio Ambiente - MMA. Portaria no 443, de 17 de dezembro de 2014. Reconhece como espécies da flora brasileira ameaçadas de extinção aquelas constantes da "Lista Nacional Oficial de Espécies da Flora Ameaçadas de Extinção". Disponível em: $<$ http://sintse.tse.jus.br/documentos/2014/Dez/18/portaria-no-443-de-17-dedezembro-de-2014>. Acesso em: 22 abr. 2015. 
BRUN, E.J.; SCHUMACHER, M.V.; VACCARO, S. Aspectos da ciclagem de material orgânico e nutrientes na serapilheira de florestas secundárias em Santa Tereza. In: SCHUMACHER, M.V. et al. (Orgs.) A Floresta Estacional Subtropical: Caracterização e Ecologia no Rebordo do Planalto Meridional. Santa Maria: [s.n.]. 2011, p. 195-214.

CARVALHO, P.E.R. Espécies arbóreas brasileiras. Brasília: Embrapa, v.1, 2003. 1039 p.

CARVALHO, P.E.R. Espécies arbóreas brasileiras. Brasília: Embrapa, v.2, 2006. $627 \mathrm{p}$.

CARVALHO, P.E.R. Espécies arbóreas brasileiras. Brasília: Embrapa, v.3, 2008. 593 p.

CARVALHO, P.E.R. Espécies arbóreas brasileiras. Brasília: Embrapa, v.4, 2010. $644 \mathrm{p}$.

CAZOTO, Juliana L.; TOZONI-REIS, Marília F.C. Construção coletiva de uma trilha ecológica no cerrado: pesquisa participativa em educação ambiental. Ciência \& Educação, v. 14, n. 3, p. 575-82, 2008.

CIELO-FILHO, R.; SOUZA, S.C.P.M.; LIMA, C.R.; AGUIAR, O.T.; BAITELLO, J.B.; PASTORE, J.A.. Aspectos botânicos como subsídio para a interpretação ambiental na Trilha do Jerivá: Estação Ecológica de Paranapanema, Estado de São Paulo, Brasil. IF Série Registros, v. 41, p. 19-34, 2010.

COSTA, R.G.S.; COLESANTI, M.M.A. Contribuição da percepção ambiental nos estudos das áreas verdes. RA'E GA 22, Curitiba, Departamento de Geografia UFPR, p. 238-251, 2011.

DI BITETTI, M.S.; PLACCI, G.; DIETZ, L.A. Uma visão de Biodiversidade para a Ecorregião Florestas do Alto Paraná - Bioma Mata Atlântica: planejando a paisagem de conservação da biodiversidade e estabelecendo prioridade para ações de conservação. Washington, D.C.: World Wildlife Fund, 2003.

EMPRESA BRASILEIRA DE PESQUISA AGROPECUÁRIA - EMBRAPA. Atlas climático da Região Sul do Brasil: Estados do Paraná, Santa Catarina e Rio Grande do Sul. Pelotas: Embrapa Clima Temperado; Colombo: Embrapa Florestas, 2011. $336 \mathrm{p}$.

ENGEL, V.L.; FONSECA, R.C.B.; OLIVEIRA, R.E. Ecologia de lianas e o manejo de fragmentos florestais.Série Técnica IPEF, v. 12, n. 32, p.43-64, dez. 1998.

FORZZA, R.C. et al. Lista de espécies da flora do Brasil. Jardim Botânico do Rio de Janeiro, 2015.2 Disponível em: $<$ http://floradobrasil.jbri.gov.br/jabot/floradobrasil/FB128482>. Acesso em: 16 abr. 2015.

HUBBELL, S.P.; FOSTER, R.B. Canopy gaps and the dynamics of a neotropical forest. In: M. J. Crawley (Ed.) Plant Ecology. Oxford: Blackwell Scientific, p.7796, 1986. 
INSTITUTO BRASILEIRO DE GEOGRAFIA E ESTATÍSTICA - IBGE. Manual técnico da vegetação brasileira: sistema fitogeográfico, inventário das formações florestais e campestres, técnicas e manejo de coleções botânicas, procedimento para mapeamento. 2. ed. rev. e ampl. Rio de Janeiro: IBGE Coordenação de Recursos Naturais e Estudos Ambientais, 2012.

LEITÃO FILHO, H.F.; MORELLATO, P.C. (Orgs.) Ecologia e preservação de uma floresta tropical urbana: Reserva de Santa Genebra. Campinas, SP: Editora da UNICAMP, 1995. $136 \mathrm{p}$.

LIMA, R.A. F. D. Estrutura e regeneração de clareiras em Florestas Pluviais Tropicais. Revista Brasil. Bot., v.28, n.4, p.651-670, out.- dez 2005.

LORENZI, H. Árvores brasileiras: manual de identificação e cultivo de plantas arbóreas nativas do Brasil. 1 ed. Nova Odessa: Editora Plantarum, 1992, v. 1, $384 \mathrm{p}$.

LORENZI, H. Árvores brasileiras: manual de identificação e cultivo de plantas arbóreas nativas do Brasil. 2 ed. Nova Odessa: Editora Plantarum, 1998, v. 2, $352 \mathrm{p}$.

MATELÂNDIA. Lei no 1403 de 20 de Setembro de 2004. Dispõe sobre a criação do Parque Ecológico Farroupilha e dá outras providências. Câmara Municipal de Matelândia, 21 set, 2004.

MENGHINI, F.B. As trilhas interpretativas como recurso pedagógico: caminhos traçados para a educação ambiental. 2005. Dissertação - Programa de Mestrado Acadêmico em Educação, UNIVALE, Itajaí (SC), 2005.

NELSON, S.P. Uso Público nas Unidades de Conservação. In: CASES, M.O. (Org.). Gestão de unidades de conservação: compartilhando uma experiência de capacitação. Brasília, 2012. p. 215-237. Disponível em: $<$ http://www.wwf.org.br>. Acesso em: 5 nov. 2014.

ODUM, E.P.; BARRETT, G.W. Fundamentos de Ecologia. [tradução Pégasus Sistemas e Soluções]. São Paulo: Thomson Learning, 2007. Tradução da $5^{\text {a }}$ edição norte-americana. $612 \mathrm{p}$.

OLIVEIRA, J.C.C.; BARBOSA, J.H.C. Roteiro para criação de unidades de conservação municipais. Brasília: Ministério do Meio Ambiente, 2010. 68 p.

OLIVEIRA JR, C.J.F., NEVES, Y.T.R., JUNQUEIRA, P.S. População caiçara, Mata Atlântica e situação atual do palmito (Euterpe edulis MART) na região do rio Una da Aldeia (Iguape - SP), entorno da estação ecológica Juréia-Itatins. Revista Árvore, n. 6, v. 34, p. 1065 - 1073, 2010.

PARANÁ. Secretaria de Estado do Meio Ambiente. Lista Vermelha de Plantas Ameaçadas de Extinção no Estado do Paraná. Curitiba: SEMA, 1995. 177p. PREFEITURA MUNICIPAL DE MATELÂNDIA. Plano de manejo - parque ecológico farroupilha. Matelândia, 2010. 42 p. 
PUIG, H.; tradução de Maria Leonor Frederico Rodrigues Loureiro. A floresta tropical úmida. São Paulo: Editora UNESP Imprensa Oficial do Estado de São Paulo; França: Institut de Rechérche pour le Développement, 2008. 496 p.

PUTZ, F. E. The Natural History of Lianas on Barro Colorado Island. Ecology, Panama, p. 1713 - 1724, 1984.

RICKLEFS, R.E. A Economia da Natureza. $6^{\underline{a}}$ ed. Rio de Janeiro: Editora Guanabara Koogan, 2010.

ROTTA, E.; BELTRAMI, L.C.C.; ZONTA, M. Manual de Prática de Coleta e Herborização de Material Botânico. Colombo: Embrapa Florestas, 2008. 31 p. Disponível em: <http://www.cnpf.embrapa.br/publica/seriedoc/edicoes.htm>. Acesso em: 5 set. 2014.

SÃO PAULO. Manejo de trilha: um manual para gestores. São Paulo: Instituo Florestal. n. 35. p. 1-74. Maio, 2008. (Série Registros).

SILVA, D.M.; JÚNIOR LORENCINI, Á. A relação entre trilhas interpretativas, Interpretação Ambiental e Educação Ambiental, e a importância das espécies arbóreas para essas atividades. In: Simpósio Nacional de Ensino de Ciência e Tecnologia. Anais. 2010. n. 160, Ponta Grossa.

TUNDISI, J.G.; TUNDISI, T.M. Impactos potenciais das alterações do Código Florestal nos recursos hídricos. Biota Neotrop. v. 10, n. 4, dez 2010. Disponível em:

$<$ http://www.biotaneotropica.org.br/v10n4/pt/abstract?article+bn01110042010. ISSN 1676-0603>. Acesso em 6 nov. 2014.

UHL, C.; VIEIRA, I.C.G. Ecological impacts of selective logging in the Brazilian Amazon: a case study from the Paragominas Region of the State of Pará. Biotropica, v. 21, n. 2, p. 98-106, 1989. Disponível em: $<$ http://www.jstor.org/discover $/ 10.2307 / 2388700$ ?uid=2485298087\&uid=2134\&u $\mathrm{id}=20564 \&$ uid $=3737664 \&$ uid $=5909624 \&$ uid $=2 \&$ uid $=70 \&$ uid $=3 \&$ uid $=20563 \&$ uid $=$

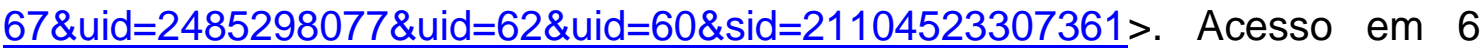
nov. 2014. 